area, and with the same depositional characteristics, were analysed to evaluate the concentration and isotope composition of lead from the local environment. Samples of modern human bone and solder from food tins manufactured in the 1880 s were included as additional controls.

The results of the lead isotope analyses are presented in the figure. The variation in the isotope ratios of the Franklin expedition samples is only slightly greater than the analytical uncertainty. The mean ${ }^{206} \mathrm{~Pb} /{ }^{204} \mathrm{~Pb},{ }^{207} \mathrm{~Pb} /{ }^{204} \mathrm{~Pb}$ and ${ }^{208} \mathrm{~Pb} /{ }^{204} \mathrm{~Pb}$ ratios, with 1o uncertainty (for the tissue samples $(n=9)$ were $18.46 \pm 0.03,15.64 \pm 0.01$, $38.48 \pm 0.04$ and for the solder samples $(n=10) \quad 18.46 \pm 0.02,15.64 \pm 0.01,38.50$ \pm 0.04 .). The slight spread in lead isotope values was expected as not all of the lead present in the tissues would have been acquired during the expedition.

Differential environmental exposures before the expedition would have assured a wide variety of isotopic ratios in the tissues of the various crewmen. The close clustering of isotope ratios, however, indicates that most of the lead in the tissues came from a single dominant source as the variability seen in the ratios is consistent with that observed when a small amount of lead from one source is mixed with a large amount of lead from another source; only a slight shift occurs in the isotopic ratios from that of the dominant contributor.

The isotope composition of lead in the tissues from the expedition members does indeed closely match that of the solder from the food tins. We conclude, therefore, that the toxic lead levels thought to be responsible for the demise of the expedition members were derived from the tinned foods.

WALTER KOWAL

OWEN B. BEATTIE

HALFDAN BAADSGAARD*

Departments of Anthropology

and Geology*,

University of Alberta,

Edmonton, Alberta T6G 2 E3

Canada

Peter M. Krahn

Riyadh Al Kharj Hospital

Programme,

PO Box 41726, Riyadh,

Saudi Arabia 11531

1. Beattie, O. The Muskox 33, 68-77 (1983)

2. Kowal, W. Krahn, P. \& Beattie, 0. Int. J. envir, analyt. Chem. 35, 119-126 (1989)

3. Beattie, 0 . in The Franklin Era in Canadian Arctic History: 1845-59 pap. No. 131 (ed. Sutherland, P.) 141-148 (National Museum of Man, Ottawa, 1985).

4. Russel, R.D. \& Farquhar, R.M. Lead Isotopes in Geology (Interscience, New York, 1960)

\section{Scientific Correspondence}

Scientific Correspondence is intended to provide a forum in which readers may raise points of a scientific character. They need not arise out of anything published in Nature. In any case, priority will be given to letters of less than 500 words and five references.

\title{
The great fireworks illusion
}

SIR-The optical illusion (Nature 341, $492 ; 1989$ ) during pyrotechnic displays by which all exploding fragments appear erroneously to move toward the observer has a close parallel in the apparent motion of rotating searchlight beams.

In some cities, such as ours, powerful trailer-mounted searchlights are used to call attention to special sales and giveaways of merchandise when new retail stores open. Inclined searchlight beams stab the night sky as the light sources and reflectors rotate on a stable base. To an observer several miles away, the beams reaching into the sky appear to oscillate back and forth rather than to rotate.

The length of the lighted path in the sky appears longest when the vertical plane passing through the inclined beam is orientated at right angles to the view of the observer. As the inclined beam swings away from or towards the observer, the apparent length of the lighted sky path is foreshortened. The eye and brain consistently tend to interpret the observed foreshortening as a motion of the searchlight beam toward the observation point, rather than away from it.

As a result, the observer is prone to conclude that the motion of the searchlight is oscillatory rather than rotatory. The true motion is clear only if there is a low cloud cover. In that case, the searchlight illuminates a moving spot on the base of the clouds and the circular motion of the spot reveals the true rotatory motion of the beam.

I do not understand why this particular optical illusion should be so strong, but it is typically compelling without clouds to provide a reliable frame of reference.

WILLIAM R. DICKINSON

\section{Department of Geosciences,}

University of Arizona,

Tucson, Arizona 85721,

USA

SIR-Regarding the letter from J. D. Daniels (Nature 341, 492; 1989), I have observed a similar illusion when driving at night: the rear light of the car in front sometimes appears to be approaching even when I do not subsequently catch up with that car. As with Daniels' firework example, this does not occur in daylight, but here there is little, if any, intensification of the light to give the illusion that it is 'getting larger', or drawing nearer. It also does not occur in heavy traffic, suggesting that the illusion is a function of the absence of local visual cues to depth. That other drivers who do not share my severe short sight seldom confirm the illusion would support this interpretation: in poor illumination they see faint cues better than I.

I suspect that this is a 'default option' of the human visual system. In the absence of any good visual cues, objects are assumed to be approaching the observer. This would make good evolutionary sense: better assume that an object is approaching, and take appropriate action, than assume that it is stationary (or withdrawing) and take inappropriate inaction.

\section{Cambridge Laboratory,}

PA Consulting Group,

Melbourn, Royston,

Hertfordshire SG8 6DP,

UK

SIR-The phenomenon pointed out by Daniels (Nature 341, 492; 1989) becomes less surprising when its definition is appropriately changed. According to Daniels' definition, which I shall call analytical, there are several moving objects, each of which traces a predictable trajectory, but, surprisingly, some of the expected trajectories do not appear.

On the other hand, if we consider the firework as a single object, or as a growing sphere composed of self-luminescent fragments, it is possible to say that the observer does not distinguish the side of the sphere opposite to his cone of observation. I shall call this definition structuralist.

Levi-Strauss is said to have appreciated the value of structuralism by observing a dandelion fruit and considering that its form depends upon the arrangement of the pappi. There is a remarkable analogy between the forms of dandelions and fireworks. Clearly, partially empty spheres of this kind do not necessarily show the side opposite to the observer. A little experimentation will for example, show that whether the pappi of the opposite side of a dandelion are distinguishable depends on the distance of the observer from the flower.

Although with the analytical definition there is a 'magical' phenomenon to explain, the structuralist definition is an example of a common situation that needs clarifying. Thus the structuralist perspective turns the question about the illusion from strong to weak. This could be an example of how, in some circumstances, it is rational to maintain a certain level of complexity in an abstract reduction (structuralism, holism, system theory or, in this case, as perception is involved, also Gestalt psychology), despite the fact that there seem to be simpler elementary units. It is noteworthy that here a holistic perspective results in a more economic hypothesis than a reductionist one.

Via Tevere,

20 Rome, 00198 /taly 